\title{
Association of TNFAIP8 gene polymorphisms with endometrial cancer in northern Chinese women
}

Tianbo Liu ${ }^{*^{*}} \mathbb{0}$, Liangliang Jiang ${ }^{1}$, Libo Yu ${ }^{1}$, Tingting $\mathrm{Ge}^{1}$, Jing Wang ${ }^{1}$ and Hongyu Gao ${ }^{2^{*}}$

\begin{abstract}
Background: Tumor necrosis factor-a-induced protein 8 (TNFAIP8) presented a elevated expression in endometrial cancer (EC). However, the relationship of TNFAIP8 gene polymorphisms with EC risk remains unclear. This case-control study aimed to investigate the effect of single nucleotide polymorphisms (SNPS) in TNFAIP8 on northern Chinese women with EC.

Methods: SNP rs11064, rs1045241, and rs 1045242 in TNFAIP8 were successfully genotyped in 248 cancer-free controls and 226 ECs by SNaPshot method, respectively. Logistic regression was performed to assess relationship of SNPs with EC risk. The relationships of SNPs with clinicopathological variables were evaluated by Chi-square test or Student's t-test or Fisher's text.

Results: The minor alleles of rs 11064 in TNFAIP8 were strongly associated with EC risk, with adjust odds ratio (OR) of 1.719 (95\% Cl 1.180-2.506, $\mathrm{P}=0.005$ ). The minor allele of $\mathrm{rs} 1045242$ in the TNFAIP8 gene was strongly associated with with $\mathrm{EC}$ risk (adjust OR: 1.636, 95\% Cl 1.107-2.417, $\mathrm{P}=0.014$ ). rs 11064 SNPs correlated with TNFAIP8 protein expression in $E C(P=0.015)$. For $r s 1045242$, patients with $A G+G G$ presented higher TNFAIP8 protein expression than that with AA $(P=0.020)$. It also showed that SNP rs 1064 was associated with advanced FIGO stage $(P=0.001)$, deep myometrial invasion ( $P=0.047)$, and lymph node metastasis $(P=0.048)$ under the codominant model in $E C s$.
\end{abstract}

Conclusions: SNP rs11064 in TNFAIP8 increased EC risk and significantly related with its protein expression in northern Chinese women.

Keywords: TNFAIP8, Polymorphism, Endometrial cancer, Protein expression, Susceptibility

\section{Background}

Endometrial cancer (EC) presents the fourth most often cancer among female around the world [1]. Presently, the incidence of EC continues to rise in developing countries, and the age of diagnosis is getting younger. Besides, all kinds of genetic mutations and abnormal activation of relevant signaling pathways are intimately associated with the occurrence and development of EC [2]. Therefore, it

\footnotetext{
*Correspondence: skyliu_1030@163.com; hydgaohongyu@163.com ${ }^{1}$ Department of Gynecology, Harbin Medical University Cancer Hospital, Harbin Medical University, 150 Haping Road, Harbin 150081, China ${ }^{2}$ Department of Gastroenterologic Surgery, Harbin Medical University Cancer Hospital, Harbin Medical University, 150 Haping Road, Harbin 150081, China
}

is needful to investigate the underlying mechanisms of these genes as clinical molecular markers in EC.

TNFAIP8 was first found in primary human head and neck squamous cell carcinoma (HNSCC) cell line and its matched metastatic cell line which were from the same patient through analysis of the expression profile [3]. Accumulating data indicates that upregulation of TNFAIP8 participated in tumor cell progression, proliferation, invasion, migration, apoptosis, and chemotherapy resistance in different types of tumor [4-18]. Previously, we have demonstrated elevated expression of TNFAIP8 mRNA and protein in tissues with EC, and its upregulation negatively affect prognosis of EC [10]. Nevertheless, the potential molecular mechanism of the abnormality of TNFAIP8 in EC remains to be unclear.

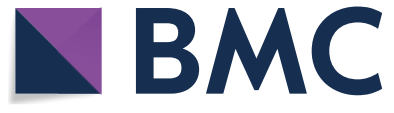

(c) The Author(s) 2019. This article is distributed under the terms of the Creative Commons Attribution 4.0 International License (http://creativecommons.org/licenses/by/4.0/), which permits unrestricted use, distribution, and reproduction in any medium, provided you give appropriate credit to the original author(s) and the source, provide a link to the Creative Commons license, and indicate if changes were made. The Creative Commons Public Domain Dedication waiver (http://creativecommons.org/ publicdomain/zero/1.0/) applies to the data made available in this article, unless otherwise stated. 
As is known to all that the polymorphisms of gene could influence gene expression. Therefore, we assume that the polymorphisms of TNFAIP8 may be correlated with protein expression and may impact EC risk and prognostic factors.

We aimed to explore TNFAIP8 polymorphisms and their association with EC risk. We also examined the association between TNFAIP8 polymorphisms and prognostic factors in EC.

\section{Materials and methods Study population}

This case-control study included 226 cases with EC and 248 cancer-free control samples. All subjects were ethnically homogenous Chinese and resided in the Heilongjiang province of China. Cases primarily diagnosed with EC were treated with hysterectomy, bilateral salpingooophorectomy, pelvic and/or paraaortic lymphadenectomy, partial omentectomy and peritoneal washing for cytology at the Department of Gynecology, Harbin Medical University Cancer Hospital. All the patients did not have radiotherapy or chemotherapy history before surgical operations. The participants were genetically not related in three generations. After providing informed consent, each participant was interviewed to collect detailed information on demographic characteristics and provided $5 \mathrm{~mL}$ venous blood from September 2015 to February 2017. This study was approved by the Medical Ethics Committee of Harbin Medical University, Harbin, China.

\section{SNPs genotyping of TNFAIP8}

We performed a combined analysis of functional significance and Tag SNP strategies to select three potential functional SNPs of the TNFAIP8 gene from the dbSNP and HapMap databases. The three SNPs were rs11064, rs1045241, and rs1045242, respectively. Genomic DNA was obtained from the whole blood, and was isolated from EDTA anti-coagulated whole blood using the AxyPrep Blood Genomic DNA Miniprep Kit (Axygen Biotechnology, Union City, CA, USA). The SNaPshot SNP assay was carried out to detect the dimorphism at the seven SNP loci. The resulting data were analyzed with GeneMapperTM 4.0 Software (Applied Biosystems, Foster City, CA, USA). To ensure quality-control, genotyping was done without knowledge of case/control status of the subjects, and a $5 \%$ random sample of cases and controls was genotyped twice by different persons; the reproducibility was $100 \%$.

\section{Immunohistochemistry (IHC)}

All 226 primary EC tissues were stained by IHC. IHC staining for TNFAIP8, estrogen receptor (ER), progesterone receptor (PR), P53 and Ki67 were performed using the Two-Step IHC Detection Reagent (PV-6001) kit (Zhong Shan Golden Bridge Biological Technology Inc., Beijing, China). The antibodies dilutions and sources were as follows: rabbit polyclonal antibodies for TNFAIP8 (1:100; Abcam), monoclonal antibodies for ER (1:100; Ventana), PR (1:70; Dako), P53 (1:600; Dako) and Ki67 (1:250; Dako). TNFAIP8 status was scored as our previous research [7]. ER and PR status were scored by the current American Society of Clinical Oncology (ASCO)/College of American Pathologists (CAP) guidelines [19]. All the samples were considered to be positive for ER or PR when at least $1 \%$ of the tumor cell nuclei were stained. The samples with nuclear staining in at least $10 \%$ of tumor cells were considered positive for P53 [20]. And the positivity threshold for Ki67 was more than $14 \%$ of tumor cells with stained nuclei [21].

\section{Statistical analysis}

The genotype frequencies were tested for Hardy-Weinberg equilibrium using the Chi-square test among the controls. Differences between cases and controls in demographic characteristics were evaluated by the Chisquare test or Fisher's text (for categorical variables) or Student's t-test (for continuous variables). The association between TNFAIP8 gene polymorphisms and protein expression was evaluated by the Chi-square test or Fisher's text. Associations between genotypes and EC risk were estimated by computing odds ratios (ORs) and 95\% confidence intervals (CIs) from logistic regression with adjustment for age, smoking history, BMI, and menopausal status.

\section{Results}

\section{Subject characteristics}

The 226 cases and 248 controls were similar with regard to age at interview, parity, diabetes and smoking history (Table 1). However, there were significant differences between cases and controls in the BMI $(\mathrm{P}<0.001)$, age at menarche $(\mathrm{P}=0.003)$, menopausal status $(\mathrm{P}<0.001)$, and hypertension $(\mathrm{P}<0.001)$.

\section{Relationships of TNFAIP8 SNPs with EC risk}

The allele and genotype distributions for all SNPs in cases and controls were shown in Table 2. The observed genotype frequencies of three SNPs followed Hardy-Weinberg equilibrium among the controls $(\mathrm{P}>0.05$ for all three SNPs).

The results showed that the minor allele of rs11064 in the TNFAIP8 gene was strongly associated with EC in patients (crude OR: 1.593, 95\% CI 1.153-2.201, $\mathrm{P}=0.005$ and adjust OR: $1.719,95 \%$ CI 1.180-2.506, $\mathrm{P}=0.005$ ). There was no association between the minor allele of rs1045242 in the TNFAIP8 gene and EC risk (crude OR: 
Table 1 Characteristics of 226 endometrial cancer cases and 248 cancer-free controls

\begin{tabular}{lllr}
\hline Characteristics & Cases & Controls & \multicolumn{1}{c}{$\boldsymbol{P}^{\mathbf{a}}$} \\
\hline Age & $53.92 \pm 8.396$ & $53.44 \pm 8.692$ & 0.545 \\
BMI & $25.59 \pm 3.576$ & $23.79 \pm 4.919$ & $<0.001$ \\
Age at menarche & $14.60 \pm 1.497$ & $15.06 \pm 1.886$ & 0.003 \\
Menopausal status & & & $<0.001$ \\
$\begin{array}{l}\text { Pre-menopausal } \\
\text { Post-menopausal }\end{array}$ & 86 & 195 & \\
Parity & 140 & 53 & 0.905 \\
Nulliparity & 30 & 32 & \\
Multiparity & 196 & 216 & $<0.001$ \\
Hypertension & & & \\
No & 163 & 216 & 0.053 \\
Yes & 63 & 32 & \\
Diabetes & & & \\
No & 200 & 232 & \\
Yes & 26 & 16 & \\
Smoking history & & 228 & \\
No & 206 & 20 & \\
Yes & 20 & & \\
\hline
\end{tabular}

BMI body mass index

${ }^{\text {a }}$ Two-sided Chi-squared test or Fisher's test or student's t test

1.353, 95\% CI 0.968-1.892, $\mathrm{P}=0.077$ ). After adjusting for age, BMI, menopausal status, and smoking history, however, we observed that the minor allele of rs1045242 in the TNFAIP8 gene related significantly with EC risk (adjust OR: 1.636, 95\% CI 1.107-2.417, P = 0.014).

We further analyzed the effect of the genotypes of these SNPs under three different genetic models. In the logistic regression models, compared with AA genotype of rs11064, GG genotypes was associated with an increased risk of EC (adjusted OR $=2.582$, 95\% CI 1.034-6.445, $\mathrm{P}=0.042)$. This SNP was also related with an increased risk of EC under a dominant model (GG+AG vs. AA, adjust $\mathrm{OR}=1.778,95 \% \mathrm{CI} 1.134-2.782, \mathrm{P}=0.012)$. Compared with the rs1045242 AA genotype, the AG and GG genotype possibly conferred increased risk for $\mathrm{EC}$ in the dominant model (adjust OR $=1.651,95 \%$ CI 1.049-2.599, $\mathrm{P}=0.030$ ). However, no significant association with EC risk was observed for rs1045241 in the TNFAIP8 gene.

\section{Stratified analysis by age, smoking history, BMI, and menopausal status}

The results of stratified analyses are shown in Additional file 1: Table S1, Additional file 2: Table S2, Additional file 3: Table S3, and Additional file 4: Table S4. For the patients whose age was greater than 54 , in the dominant model, combined genotypes (AG + GG) of rs11064 had a 1.899-fold increase EC risk compared with the genotype
AA $(O R=1.899,95 \%$ CI $1.051-3.430, P=0.034)$. However, for patients whose age was no more than 54, we did not observe the association between genotypes and EC risk. For patients who have no smoking history, the minor allele of rs1045242 significantly increased EC risk under co-dominant and dominant models $(\mathrm{P}<0.05)$. Furthermore, for patients whose BMI was greater than 25, in the dominant model, combined genotypes (AG+GG) of rs11064 had a 2.358-fold increase EC risk compared with the genotype AA (OR $=2.358,95 \%$ CI 1.133-4.906, $\mathrm{P}=0.022)$. Interestingly, when evaluating menopausal status, we found that the minor allele of rs1045242 strongly increased EC risk under co-dominant and dominant models $(\mathrm{P}<0.05)$ in patients who were at pre-menopausal. In addition, we observed that for patients who were at pre-menopausal, combined genotypes (AG+GG) of rs11064 had a 1.747-fold increase EC risk compared with the genotype AA (OR $=1.747$, 95\% CI 1.027-2.972, $\mathrm{P}=0.040)$.

\section{Associations between TNFAIP8 SNPs and TNFAIP8 protein expression}

The TNFAIP8 protein expression in EC tissue was shown in Fig. 1, and the immunostaining were localized within the cytoplasm of tumor cells. SNP rs11064 was significantly associated with TNFAIP8 protein expression under the codominant model $(P=0.005$, Table 3$)$. Moreover, patients with genotypes AG and GG were significantly associated with increased TNFAIP8 protein expression under the dominant model $(\mathrm{P}=0.015$, Table 2).

SNP rs1045242 was correlated with TNFAIP8 protein expression under the dominant model $(\mathrm{P}=0.020$, Table 3). However, the correlation with TNFAIP8 protein expression was not found in the codominant model $(\mathrm{P}=0.060$, Table 3$)$.

No significant association was observed between SNP rs1045241 and TNFAIP8 protein expression under the codominant model and the dominant model $(\mathrm{P}=0.229$; $\mathrm{P}=0.099$, respectively, Table 3 ).

\section{Associations between TNFAIP8 SNPs and the clinical characteristics of EC cancer}

The association of rs11064, rs1045241 and rs1045242 polymorphisms with clinicopathological characteristics is shown in Table 4. SNP rs11064 had a significant association with FIGO stage $(\mathrm{P}=0.011)$, depth of myometrial invasion $(\mathrm{P}=0.047)$, and lymph node metastasis $(\mathrm{P}=0.048)$ under the codominant model. However, these correlations were not found under dominant model. For SNP rs1045242, it was found that the patients with genotypes AG and GG were more likely to have advanced FIGO stage compared to the patients with genotype AA 
Table 2 Genotype frequencies of TNFAIP8 gene polymorphism among patients and controls and their associations with the susceptibility of endometrial cancer

\begin{tabular}{|c|c|c|c|c|c|c|c|}
\hline Variables & Cases (\%) n= 226 & Controls (\%) $n=248$ & $P^{a}$ & Crude OR $(95 \% \mathrm{Cl})$ & $P$ & Adjust OR (95\% CI) & $P^{\mathrm{b}}$ \\
\hline \multicolumn{8}{|l|}{ Genotypes } \\
\hline rs11064 & & & 0.029 & & & & \\
\hline AA & $138(61.1)$ & $178(71.8)$ & & & & & \\
\hline$A G$ & $70(31.0)$ & $60(24.2)$ & & $1.505(0.998-2.268)$ & 0.051 & $1.571(0.972-2.539)$ & 0.065 \\
\hline $\mathrm{GG}$ & $18(7.9)$ & $10(4.0)$ & & $2.322(1.039-5.190)$ & 0.040 & $2.582(1.034-6.445)$ & 0.042 \\
\hline$A G+G G$ & $88(38.9)$ & $70(28.2)$ & & $1.622(1.104-2.382)$ & 0.014 & $1.778(1.134-2.782)$ & 0.012 \\
\hline rs1045241 & & & 0.529 & & & & \\
\hline CC & $143(63.3)$ & $167(67.3)$ & & & & & \\
\hline $\mathrm{CT}$ & $71(31.4)$ & $72(29.1)$ & & $1.152(0.775-1.712)$ & 0.485 & $1.144(0.906-2.299)$ & 0.122 \\
\hline $\mathrm{TT}$ & $12(5.3)$ & $9(3.6)$ & & $1.557(0.638-3.802)$ & 0.331 & $1.980(0.699-5.607)$ & 0.198 \\
\hline $\mathrm{CT}+\mathrm{TT}$ & $83(36.7)$ & $81(32.7)$ & & 1.197 (0.819-1.748) & 0.353 & $1.501(0.961-2.344)$ & 0.074 \\
\hline rs1045242 & & & 0.197 & & & & \\
\hline AA & $144(63.7)$ & $177(71.4)$ & & & & & \\
\hline$A G$ & $74(32.7)$ & $65(26.2)$ & & 1.399 (0.939-2.086) & 0.099 & $1.568(0.980-2.507)$ & 0.061 \\
\hline GG & $8(3.6)$ & $6(2.4)$ & & $1.639(0.556-4.831)$ & 0.370 & 2.695 (0.799-9.084) & 0.110 \\
\hline$A G+G G$ & $82(36.3)$ & $71(28.6)$ & & $1.420(0.965-2.089)$ & 0.076 & 1.651 (1.049-2.599) & 0.030 \\
\hline \multicolumn{8}{|l|}{ Alleles } \\
\hline \multicolumn{8}{|l|}{ rs11064 } \\
\hline A & $346(76.5)$ & $416(83.9)$ & & & & & \\
\hline G & $106(23.5)$ & $80(16.1)$ & 0.005 & $1.593(1.153-2.201)$ & 0.005 & $1.719(1.180-2.506)$ & 0.005 \\
\hline \multicolumn{8}{|l|}{ rs1045241 } \\
\hline C & $357(79.0)$ & $406(81.9)$ & & & & & \\
\hline $\mathrm{T}$ & $95(21.0)$ & $90(18.1)$ & 0.265 & $1.200(0.870-1.656)$ & 0.265 & $1.457(1.001-2.120)$ & 0.050 \\
\hline \multicolumn{8}{|l|}{ rs1045242 } \\
\hline A & $362(80.1)$ & $419(84.5)$ & & & & & \\
\hline G & $90(19.9)$ & $77(15.5)$ & 0.077 & $1.353(0.968-1.892)$ & 0.077 & $1.636(1.107-2.417)$ & 0.014 \\
\hline
\end{tabular}
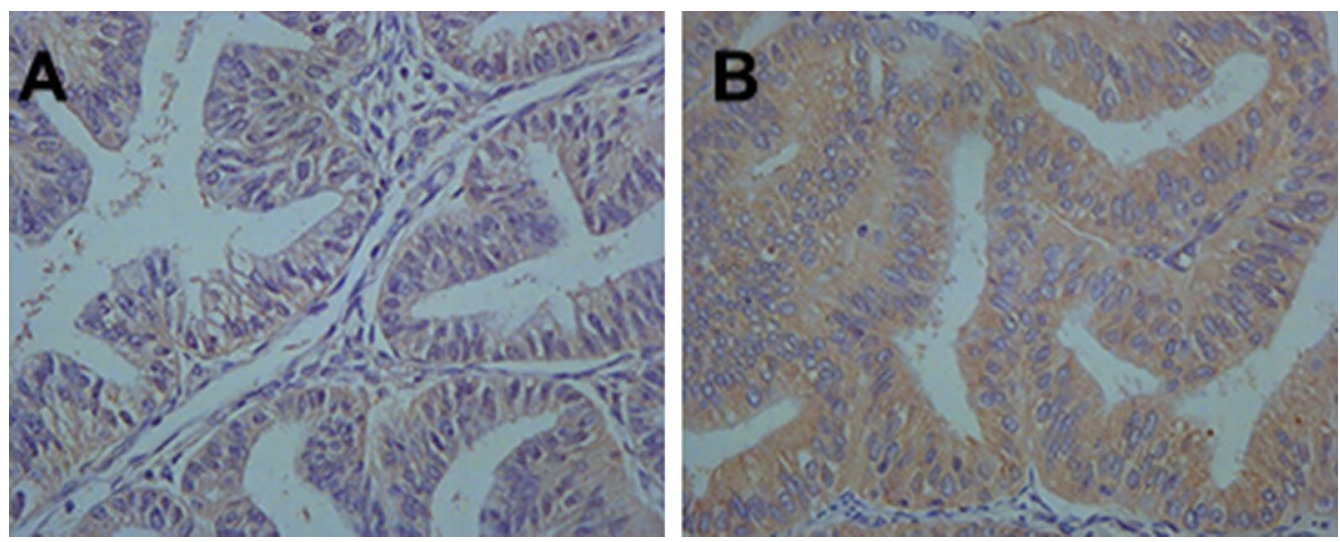

Fig. 1 Immunohistochemical staining of TNFAIP8 protein in endometrial cancer tissues. TNFAIP8 immunoreactivity was observed mainly in the cytoplasm. Staining for each specimen is shown at magnification $\times 400$. TNFAIP8 protein low expression slides (a); TNFAIP8 protein high expression slides (b) 
Table 3 Association of different SNPs in the TNFAIP8 gene with TNFAIP8 protein expression from 226 patients with endometrial cancer

\begin{tabular}{cccc}
\hline SNP & \multicolumn{2}{c}{ TNFAIP8 expression } & $P^{\mathbf{a}}$ \\
\cline { 2 - 3 } & High (\%) (n=85) & Low (\%) (n= 141) & \\
\hline Genotypes & & & \\
rs11064 & & & \\
AA & $42(49.4)$ & $96(68.1)$ & 0.015 \\
AG & $33(38.8)$ & $37(26.2)$ & 0.005 \\
GG & $10(11.8)$ & $8(5.7)$ & \\
AG + GG & $43(50.6)$ & $45(31.9)$ & \\
rs1045241 & & & 0.229 \\
CC & $48(56.5)$ & $95(67.4)$ & 0.099 \\
CT & $32(37.6)$ & $39(27.7)$ & \\
TT & $5(5.9)$ & $7(4.9)$ & \\
CT+TT & $37(43.5)$ & $46(32.6)$ & 0.060 \\
rs1045242 & & & 0.020 \\
AA & $46(54.1)$ & $98(69.5)$ & \\
AG & $34(40.0)$ & $3(28.4)$ & \\
GG & $5(5.9)$ & $43(30.5)$ & \\
AG + GG & $39(45.9)$ & &
\end{tabular}

${ }^{a}$ Two-sided Chi-squared test or Fisher's test

$(\mathrm{P}=0.041)$. Furthermore, we observed the patients with genotypes AG and GG were more likely to have deeper myometrial invasion $(\mathrm{P}=0.034)$. Yet, these correlations were not found under codominant model. No significant associations could be found between these two SNPs and EC patients' histologic grade, histological type, LVSI, CA-125 level, P53, ER, PR, and Ki67 expression. Additionally, in this study, there were no significant associations between rs 1045241 and all disease characters.

\section{Discussion}

In this study, we genotyped three polymorphisms in the TNFAIP8 gene, rs11064, rs1045241, and rs1045242, and evaluated their association with its protein expression and with EC risk in women from Heilongjiang Province, China. We found that SNPs rs11064 and rs1045242 in TNFAIP8 gene positively correlated with elevated risk of EC in northern Chinese women. Our studies also indicated significant relationships of SNPs rs11064 and rs1045242 with TNFAIP8 protein expression.

TNFAIP8 locates on chromosome 5q23.1, a $21 \mathrm{kDa}$ cytosolic protein, includes 11 exons and 10 introns, spans about 13.5 KB of genomic DNA. Research has indicated the relationship of TNFAIP8 gene polymorphisms with susceptibility of cervical cancer. TNFAIP8 rs11064 polymorphism especially the variant $G$ allele was associated with cervical cancer risk in Chinese people, indicating a risk allele [8]. Consistently with previous study, our study showed that the G allele of rs11064 increased a 1.791-fold risk for EC in northern Chinese women, which was never reported before. In addition, our study also revealed that the $G$ allele of rs1045242 increased a 1.636-fold risk for EC. Recently, it reported that rs1045241T was related with a high risk of non-Hodgkin's lymphoma among Chinese population [22].

We also found that the $\mathrm{G}$ allele of rs11064 had a possible trend of correlation with advanced FIGO stage, deep myometrial invasion, and lymph node metastasis in EC patients. Our previous study revealed that TNFAIP8 overexpression in ECs correlated with advanced FIGO stage, deep myometrial invasion, lymphovascular space invasion, and lymph node metastasis [10]. These results revealed that SNPs in TNFAIP8 gene might associate with its mRNA and protein expression and increase susceptibility to EC. Although polymorphisms in coding region may change protein expression, numbered researches have explored the association between TNFAIP8 SNPs and its protein expression. Our results suggest that the rs11064 polymorphism positively correlated with TNFAIP8 protein expression, being consistent with that in cervical cancer [8]. However, elaborate mechanisms that intronic polymorphisms affecting protein expression remain unknown.

In addition, our study indicated that the TNFAIP8 rs1045242 polymorphism had a meaningful joint effect with no smoking history and pre-menopausal on strengthening the risk of cancer. Smoking history and the status of menopausal are both important risk factors for EC, but the mechanism underlying this association is unknown. Our results demonstrated that TNFAIP8 may by another way take a part in the development of EC without depending on smoking and status of menopausal. As far as we know, this is the first report investigating the association between TNFAIP8 polymorphisms and the EC risk.

\section{In conclusion}

We firstly evaluate the relationship of TNFAIP8 polymorphisms with its protein expression and with EC risk in women from northern China. This case-control study indicates that SNPs rs11064 and rs1045242 in TNFAIP8 gene are associated with increased risk for EC among northern Chinese women. Furthermore, SNPs rs11064 was associated with TNFAIP8 protein expression. Our findings supply a novel idea, TNFAIP8 disturbing EC, and indicate that TNFAIP8 gene may be an underlying marker for early detection and a target for molecular targeted therapy in EC. Further investigation of these findings is warranted in analyses involving combinations with other alleles. 
Table 4 The association between rs11064, rs1045241 and rs1045242 and clinicopathological characteristics of endometrial cancer

\begin{tabular}{|c|c|c|c|c|c|c|c|c|c|c|c|c|c|c|c|}
\hline \multirow[t]{2}{*}{ Characteristics } & \multicolumn{4}{|c|}{ rs11064 } & \multirow[t]{2}{*}{$P^{a}$} & \multicolumn{4}{|c|}{ rs1045241 } & \multirow[t]{2}{*}{$P^{a}$} & \multicolumn{4}{|c|}{ rs1045242 } & \multirow[t]{2}{*}{$P^{a}$} \\
\hline & AA & AG & GG & $A G+G G$ & & $\mathrm{CC}$ & $\mathrm{CT}$ & $\mathrm{TT}$ & $\mathrm{CC}+\mathrm{CT}$ & & AA & AG & GG & $A G+G G$ & \\
\hline FIGO stage & & & & & 0.011 & & & & & 0.174 & & & & & 0.103 \\
\hline I & 108 & 60 & 10 & 70 & 0.425 & 115 & 54 & 9 & 63 & 0.075 & 114 & 58 & 6 & 64 & 0.041 \\
\hline$\|$ & 23 & 6 & 3 & 9 & & 22 & 8 & 2 & 10 & & 24 & 7 & 1 & 8 & \\
\hline III-IV & 7 & 4 & 5 & 9 & & 6 & 9 & 1 & 10 & & 6 & 9 & 1 & 10 & \\
\hline Histologic grade & & & & & 0.718 & & & & & 0.678 & & & & & 0.658 \\
\hline G1 & 56 & 29 & 5 & 34 & 0.966 & 57 & 28 & 5 & 33 & 0.554 & 56 & 30 & 4 & 34 & 0.383 \\
\hline G2 & 60 & 29 & 11 & 40 & & 66 & 28 & 6 & 34 & & 68 & 29 & 3 & 32 & \\
\hline G3 & 22 & 12 & 2 & 14 & & 20 & 15 & 1 & 16 & & 20 & 15 & 1 & 16 & \\
\hline Histological type & & & & & 0.445 & & & & & 0.469 & & & & & 0.464 \\
\hline $\mathrm{EC}$ & 112 & 57 & 17 & 74 & 1.000 & 114 & 61 & 11 & 72 & 0.182 & 116 & 62 & 8 & 70 & \\
\hline Non-EC & 26 & 13 & 1 & 14 & & 29 & 10 & 1 & 11 & & 28 & 12 & 0 & 12 & \\
\hline Depth of MI & & & & & 0.047 & & & & & 0.153 & & & & & 0.088 \\
\hline$<50 \%$ & 95 & 53 & 17 & 70 & 0.077 & 98 & 98 & 8 & 65 & 0.114 & 97 & 60 & 6 & 66 & 0.034 \\
\hline$\geq 50 \%$ & 43 & 17 & 1 & 18 & & 45 & 45 & 4 & 18 & & 47 & 14 & 2 & 16 & \\
\hline LVSI & & & & & 0.708 & & & & & 0.338 & & & & & 0.562 \\
\hline No & 118 & 63 & 16 & 79 & 0.350 & 122 & 122 & 10 & 75 & 0.274 & 123 & 67 & 7 & 74 & 0.297 \\
\hline Yes & 20 & 7 & 2 & 9 & & 21 & 21 & 2 & 8 & & 21 & 7 & 1 & 8 & \\
\hline LN metastasis & & & & & 0.048 & & & & & 0.702 & & & & & 0.934 \\
\hline No & 122 & 62 & 12 & 74 & 0.351 & 123 & 123 & 10 & 73 & 0.679 & 124 & 65 & 7 & 72 & 0.718 \\
\hline Yes & 16 & 8 & 6 & 14 & & 20 & 20 & 2 & 10 & & 20 & 9 & 1 & 10 & \\
\hline CA-125 level & & & & & 0.261 & & & & & 0.296 & & & & & 0.115 \\
\hline$\leq 35 \mathrm{U} / \mathrm{mL}$ & 102 & 59 & 14 & 73 & 0.113 & 108 & 108 & 8 & 67 & 0.283 & 106 & 63 & 6 & 69 & 0.063 \\
\hline > 35 U/MI & 36 & 11 & 4 & 15 & & 35 & 35 & 4 & 16 & & 38 & 11 & 2 & 13 & \\
\hline P53 & & & & & 0.198 & & & & & 0.092 & & & & & 0.141 \\
\hline Negative & 75 & 34 & 13 & 47 & 0.890 & 83 & 31 & 8 & 39 & 0.108 & 84 & 33 & 5 & 38 & 0.082 \\
\hline Positive & 63 & 36 & 5 & 41 & & 60 & 40 & 4 & 44 & & 60 & 41 & 3 & 44 & \\
\hline ER & & & & & 0.631 & & & & & 0.516 & & & & & 0.706 \\
\hline Negative & 33 & 16 & 6 & 22 & 0.853 & 36 & 18 & 1 & 19 & 0.630 & 34 & 20 & 1 & 21 & 0.736 \\
\hline Positive & 105 & 54 & 12 & 66 & & 107 & 53 & 11 & 66 & & 110 & 54 & 7 & 61 & \\
\hline PR & & & & & 0.604 & & & & & 0.860 & & & & & 0.439 \\
\hline Negative & 49 & 20 & 6 & 26 & 0.353 & 49 & 23 & 3 & 26 & 0.651 & 49 & 22 & 4 & 26 & 0.722 \\
\hline Positive & 89 & 50 & 12 & 62 & & 94 & 48 & 9 & 57 & & 95 & 52 & 4 & 56 & \\
\hline Ki67 & & & & & 0.47 & & & & & 0.117 & & & & & 0.704 \\
\hline Negative & 34 & 14 & 6 & 20 & 0.743 & 33 & 20 & 1 & 21 & 0.854 & 32 & 20 & 2 & 22 & 0.435 \\
\hline Positive & 104 & 56 & 12 & 68 & & 110 & 51 & 11 & 66 & & 112 & 54 & 6 & 60 & \\
\hline
\end{tabular}

FIGO International Federation of Gynecology and Obstetrics, G1 well, G2 moderate, G3 poor, EC endometrial cancer, MI myometrial invasion, LVSI lymphovascular space involvement, $L N$ lymph node

a Two-sided Chi-squared test or Fisher's test

\section{Additional files}

Additional file 1: Table S1. Stratified analysis between TNFAIP8 SNPs and endometrial cancer risk by age.

Additional file 2: Table S2. Stratified analysis between TNFAIP8 SNPS and endometrial cancer risk by smoking history.

Additional file 3: Table S3. Stratified analysis between TNFAIP8 SNPS and endometrial cancer risk by $\mathrm{BMI}$
Additional file 4: Table S4. Stratified analysis between TNFAIP8 SNPs and endometrial cancer risk by menopausal status.

\section{Abbreviations}

TNFAIP8: tumour necrosis factor-a-induced protein 8; EC: endometrial cancer; SNPs: single nucleotide polymorphisms; OR: odds ratio; HNSCC: human head and neck squamous cell carcinoma; IHC: immunohistochemistry; ER: estrogen receptor; PR: progesterone receptor; Cls: confidence intervals. 


\section{Authors' contributions}

LTB conceived and designed the study. JLL, GTT, and YLB collected samples and processed data. GHY provided technical support. LTB and GHY analyzed data. LTB drafted the manuscript. WJ revised the manuscript. All authors read and approved the final manuscript.

\section{Acknowledgements}

Not applicable.

\section{Competing interests}

The authors declare that they have no competing interests.

\section{Availability of data and materials}

All data generated and analyzed during this study are included in this published article and its Additional files.

\section{Consent for publication}

Not applicable.

\section{Ethics approval and consent to participate}

The current study was approved by the Ethics Committee of Harbin Medical University Cancer Hospital. A written consent from each participant was obtained after they were informed the purpose of this study.

\section{Funding}

This study was supported by grants the of National Natural Science Foundation of China (81502225), the Postdoctoral Foundation of China (2015M581480), the Postdoctoral Foundation of Heilongjiang Province of China (LBH-Z15123), the Youth Elite Training Foundation of Harbin Medical University Cancer Hospital (JY2016-03), the Fundamental Research Funds for the Provincial Universities (2017LCZX71), Outstanding Youth Programme of Harbin Medical University Cancer Hospital (JCQN2019-06) and the Key Projects of Haiyan Foundation of Harbin Medical University Cancer Hospital (JJZD2019-02).

\section{Publisher's Note}

Springer Nature remains neutral with regard to jurisdictional claims in published maps and institutional affiliations.

Received: 30 January 2019 Accepted: 13 April 2019

Published online: 23 April 2019

\section{References}

1. Miller KD, Siegel RL, Lin CC, Mariotto AB, Kramer JL, Rowland JH, Stein KD, Alteri R, Jemal A. Cancer treatment and survivorship statistics, 2016. CA Cancer J Clin. 2016;66(4):271-89.

2. Eritja N, Yeramian A, Chen BJ, Llobet-Navas D, Ortega E, Colas E, Abal M, Dolcet X, Reventos J, Matias-Guiu X. Endometrial carcinoma: specific targeted pathways. Adv Exp Med Biol. 2017;943:149-207.

3. Patel S, Wang FH, Whiteside TL, Kasid U. Identification of seven differentially displayed transcripts in human primary and matched metastatic head and neck squamous cell carcinoma cell lines: implications in metastasis and/or radiation response. Oral Oncol. 1997;33(3):197-203.

4. Kumar D, Gokhale P, Broustas C, Chakravarty D, Ahmad I, Kasid U. Expression of SCC-S2, an antiapoptotic molecule, correlates with enhanced proliferation and tumorigenicity of MDA-MB 435 cells. Oncogene. 2004:23(2):612-6.

5. Hadisaputri YE, Miyazaki T, Suzuki S, Yokobori T, Kobayashi T, Tanaka N, Inose T, Sohda M, Kuwano H. TNFAIP8 overexpression: clinical relevance to esophageal squamous cell carcinoma. Ann Surg Oncol. 2012;19(Suppl 3):S589-96.

6. Liu K, Qin CK, Wang ZY, Liu SX, Cui XP, Zhang DY. Expression of tumor necrosis factor-alpha-induced protein 8 in pancreas tissues and its correlation with epithelial growth factor receptor levels. Asian Pac J Cancer Prev. 2012;13(3):847-50.
7. Liu T, Gao H, Chen X, Lou G, Gu L, Yang M, Xia B, Yin H. TNFAIP8 as a predictor of metastasis and a novel prognostic biomarker in patients with epithelial ovarian cancer. Br J Cancer. 2013:109(6):1685-92.

8. Shi TY, Cheng X, Yu KD, Sun MH, Shao ZM, Wang MY, Zhu ML, He J, Li QX, Chen XJ, Zhou XY, Wu X, Wei Q. Functional variants in TNFAIP8 associated with cervical cancer susceptibility and clinicaloutcomes. Carcinogenesis. 2013;34(4):770-8.

9. Zhang C, Kallakury BV, Ross JS, Mewani RR, Sheehan CE, Sakabe I, Luta G, Kumar D, Yadavalli S, Starr J, Sreenath TL, Srivastava S, Pollard HB, Eidelman O, Srivastava M, Kasid UN. The significance of TNFAIP8 in prostate cancer response to radiation and docetaxel and diseaserecurrence. Int J Cancer. 2013;133(1):31-42.

10. Liu T, Gao H, Yang M, Zhao T, Liu Y, Lou G. Correlation of TNFAIP8 overexpression with the proliferation, metastasis, and disease-free survival in endometrial cancer. Tumour Biol. 2014;35(6):5805-14.

11. Liu T, Xia B, Lu Y, Xu Y, Lou G. TNFAIP8 overexpression is associated with platinum resistance in epithelial ovarian cancers with optimal cytoreduction. Hum Pathol. 2014;45(6):1251-7.

12. Yang M, Zhao Q, Wang $X$, Liu T, Yao G, Lou C, Zhang Y. TNFAIP8 overexpression is associated with lymph node metastasis and poor prognosis in intestinal-type gastric adenocarcinoma. Histopathology. 2014;65(4):517-26.

13. Li Y, Jing C, Chen Y, Wang J, Zhou M, Liu X, Sun D, Mu L, Li L, Guo X. Expression of tumor necrosis factor a-induced protein 8 is upregulated in human gastric cancer and regulates cell proliferation, invasion and migration. Mol Med Rep. 2015;12(2):2636-42.

14. Xin Y, Wan DH, Wang X, Gao XJ, Xu XJ, Ju XL, Li AM. Effect of tumor necrosis factor-induced protein 8 on T-cell-mediated immunity in mice after thermal injury. J Biol Regul Homeost Agents. 2016;30(3):777-84.

15. Dong Q, Fu L, Zhao Y, Xie C, Li Q, Wang E. TNFAIP8 interacts with LATS1 and promotes aggressiveness through regulation of Hippopathway in hepatocellular carcinoma. Oncotarget. 2017;8(9):15689-703.

16. Xiao M, Xu Q, Lou C, Qin Y, Ning X, Liu T, Zhao X, Jia S, Huang Y. Overexpression of TNFAIP8 is associated with tumor aggressiveness and poor prognosis in patients with invasive ductal breast carcinoma. Hum Pathol. 2017:62:40-9.

17. Wang J, Gao H, Liu G, Gu L, Yang C, Zhang F, Liu T. Tumor necrosis factor a-induced protein 8 expression as a predictor of prognosis and resistance in patients with advanced ovarian cancer treated with neoadjuvant chemotherapy. Hum Pathol. 2018;82:239-48.

18. Xing Y, Liu Y, Liu T, Meng Q, Lu H, Liu W, Hu J, Li C, Cao M, Yan S, Huang J, Wang T, Cai L. TNFAIP8 promotes the proliferation and cisplatin chemoresistance of non-small cell lung cancer through MDM2/p53 pathway. Cell Commun Signal. 2018;16(1):43.

19. Hammond ME, Hayes DF, Dowsett M, Allred DC, Hagerty KL, Badve S, Fitzgibbons PL, Francis G, Goldstein NS, Hayes M, Hicks DG, Lester S, Love R, Mangu PB, McShane L, Miller K, Osborne CK, Paik S, Perlmutter J, Rhodes A, Sasano H, Schwartz JN, Sweep FC, Taube S, Torlakovic EE, Valenstein P, Viale G, Visscher D, Wheeler T, Williams RB, Wittliff JL, Wolff AC. American Society of Clinical Oncology/College Of American Pathologists quideline recommendations for immunohistochemical testing of estrogen and progesterone receptors in breast cancer. J Clin Oncol. 2010:28(16):2784-95

20. Coates AS, Millar EK, O'Toole SA, Molloy TJ, Viale G, Goldhirsch A, Regan MM, Gelber RD, Sun Z, Castiglione-Gertsch M, Gusterson B, Musgrove EA, Sutherland RL. Prognostic interaction between expression of p53 and estrogen receptor in patients with node-negative breast cancer: results from IBCSG Trials VIII and IX. Breast Cancer Res. 2012;14(6):R143.

21. Cheang MC, Chia SK, Voduc D, Gao D, Leung S, Snider J, Watson M, Davies S, Bernard PS, Parker JS, Perou CM, Ellis MJ, Nielsen TO. Ki67 index, HER2 status, and prognosis of patients with luminal B breast cancer. J Natl Cancer Inst. 2009:101(10):736-50.

22. Zhang Y, Wang MY, He J, Wang JC, Yang YJ, Jin L, Chen ZY, Ma XJ, Sun MH, Xia KQ, Hong XN, Wei QY, Zhou XY. Tumor necrosis factor-a induced protein 8 polymorphism and risk of non-Hodgkin's lymphoma in a Chinese population: a case-control study. PLoS ONE. 2012;7(5):e37846. 